\title{
3 Theoretical framework: causal factors and convergence expectations
}

\author{
KATHARINA HOLZINGER AND \\ CHRISTOPH KNILL
}

\section{I INTRODUCTION}

As has been shown in the previous chapter, the study of cross-national policy convergence is a highly popular research area in political science. Notwithstanding these far-reaching research efforts, it is generally acknowledged that we still have a limited understanding of the causes and conditions of policy convergence.

It is the objective of this chapter to develop the theory further by a systematic discussion of the causal factors of policy convergence and by the formulation of general theoretical expectations on policy convergence for each factor. We proceed in the following steps. First, we briefly present the central aspects we distinguish for the assessment of policy convergence. In a second step, we identify and compare different causal factors of cross-national policy convergence. Having elaborated on the major causes of policy convergence, however, we still know little about the conditions under which these factors actually lead to convergence. This is the objective of the third part of our analysis, in which we develop theoretical expectations for the different aspects of cross-national policy convergence. These hypotheses form the background for the empirical study of environmental policy convergence in Europe presented in the following chapters. Specifications of these expectations in the form of testable hypotheses that relate to the different empirical models used in this study will be presented in the respective chapters (6 and 7$)$. 


\subsection{HOW TO CONCEPTUALISE POLICY} CONVERGENCE?

For the purpose of the underlying study, we define policy convergence as any increase in the similarity between one or more characteristics of a certain policy (e.g. policy objectives, policy instruments, policy settings) across a given set of political jurisdictions /supranational institutions, states, regions, local authorities] over a given period of time. Policy convergence thus describes the end result of a process of policy change over time towards some common point, regardless of the causal processes.

(Knill 2005: 768)

This definition of policy convergence still leaves a broad range of options of how to empirically assess and evaluate similarity changes (Heichel, Pape and Sommerer 2005). In this book, we distinguish various aspects, including not only the degree, but also the direction and scope of convergence.

\subsubsection{Degree of convergence}

With respect to the degree of convergence, we first of all have to clarify the criteria on the basis of which we judge whether policies across countries are similar or not. In this context, a general distinction can be drawn between the similarity of policy outputs / the policies adopted by a government) and policy outcomes (the actual effects of a policy in terms of goal achievement). While studies on both dimensions can be found in the literature, we concentrate in the following analysis on policy outputs, as policy outcomes are only indirectly related to the causal mechanisms of convergence. They are usually affected by many intervening variables. The adoption of a programme is thus a poor predictor of its implementation.

For the measurement of similarity change, we start from the concept of sigma-convergence. According to this concept, the degree of convergence increases with the extent to which the policies of different countries have become more similar to each other over 
time. Thus, convergence degree is the decrease of standard deviation from time $t_{1}$ to $t_{2}$.

In addition to sigma-convergence, various concepts to assess the degree of cross-national policy convergence are applied in the literature. The concept of beta-convergence measures the extent to which laggard countries catch up with leader countries over time, implying, for instance, that the former strengthen their regulatory standards more quickly and fundamentally than the latter. By contrast, gamma-convergence is measured by changes of country rankings with respect to a certain policy. According to this approach, convergence increases with the degree of mobility, i.e., the extent to which country ranks change over time (Heichel, Pape and Sommerer 2005: $831-3)^{1}$

The concepts of sigma-, beta- and gamma-convergence imply different definitions and hence reference points for assessing changes in policy similarity over time (Knill 2005: 769). As will be shown in chapter 5 , it is therefore hardly surprising that we arrive at partially different assessments with regard to the degree of convergence, depending on the concrete concept applied.

In addition to the above-mentioned approaches, we develop a new and more sophisticated measurement concept based on the comparison of country pairs in chapter 6 . The pair approach allows us to measure sigma-convergence not only for metrical, but also for nominal data. Moreover, the pair approach allows for analysing the extent to which individual country pairs converge to the whole group or sub-groups of the countries under investigation.

\subsubsection{Direction of convergence}

In contrast to the degree of convergence, convergence direction indicates the extent to which similarity changes coincide with an upward or downward shift of the mean from time $t_{1}$ to $t_{2}$. Convergence at

1 The concepts of sigma-, beta-, and gamma-convergence are presented in more detail in chapter 4. 
the top or bottom presupposes therefore both a decrease of standard deviation and a shift of the mean (Botcheva and Martin 2001: 4).

The direction of convergence is usually related to the extent of state intervention or to the strictness of a regulation. Lax standards or laissez-faire policies are identified with the 'bottom', strict standards or interventionist policies with the 'top' (Drezner 2001: 59-64). The direction of convergence can best be measured whenever the policies under consideration come in degrees, which can be associated with a normative judgement on the quality of a policy. Typical examples are the levels of environmental and consumer protection or labour standards. However, it is not always easy to identify what the top and the bottom are in a policy, because there may be different value judgements. For example, in media regulation there are competing goals of restricting harmful content on the one hand and freedom of information on the other hand. However, when policy instruments are compared it seems not to make much sense to speak of directions of convergence. Instruments simply exist or not. Still the presence of a certain instrument can be considered 'the top', whereas its absence equates with 'the bottom'. Moreover, although in rare cases, a certain instrument can be assumed to provide stricter (or less strict) regulation than another one. Therefore, the analysis of direction of convergence will not only include those environmental policies from the sample used in the empirical study for which metrical data are available (standards), but also those which only produce nominal ones (instruments) (see chapter 7).

In this study, we apply a newly developed conception of so-called delta-convergence for the measurement of the direction of convergence. According to this gap approach, we measure convergence by looking at the distance (delta) of the countries' policies to a certain model, e.g., the best performing country, the least performing country, or the mean country (for details on delta-convergence see chapters 4 and 71 . According to this conception, for instance, a raceto-the-top would be indicated by the reduction of countries' distances to the top performer over time. As shown in table 3.1, the comparison 
Table 3.1 Potential configurations of convergence aspects

\begin{tabular}{|c|c|c|}
\hline $\begin{array}{l}\text { Standard } \\
\text { deviation }\end{array}$ & Regulatory mean & Interpretation \\
\hline \multirow[t]{2}{*}{ No change } & No change & $\begin{array}{l}\text { Persistence of diversity and level of } \\
\text { regulation }\end{array}$ \\
\hline & $\begin{array}{l}\text { Upward or } \\
\text { downward shift }\end{array}$ & $\begin{array}{l}\text { Persistence of diversity, but common } \\
\text { movement into the same direction }\end{array}$ \\
\hline \multirow[t]{2}{*}{ Decrease } & No change & $\begin{array}{l}\text { Less diversity, but persistence of } \\
\text { level of regulation }\end{array}$ \\
\hline & $\begin{array}{l}\text { Upward or } \\
\text { downward shift }\end{array}$ & Less diversity at the top or bottom \\
\hline \multirow[t]{2}{*}{ Increase } & No change & $\begin{array}{l}\text { More diversity, but persistence of } \\
\text { level of regulation }\end{array}$ \\
\hline & $\begin{array}{l}\text { Upward or } \\
\text { downward shift }\end{array}$ & $\begin{array}{l}\text { More diversity, but common } \\
\text { movement into the same direction }\end{array}$ \\
\hline
\end{tabular}

Source: adapted from Holzinger and Knill 2005c: 777.

between the policies in time $t_{1}$ and $t_{2}$ for a number of countries can yield different interpretations, depending on the underlying conception of convergence.

\subsubsection{Scope of convergence}

For the development of hypotheses on the degree and direction of convergence only those sub-groups of countries and policies are of theoretical interest that can be expected to be actually affected by a certain mechanism of convergence. For example, if we talk about international harmonisation we would not expect any convergence effects on countries which are not members of the international institutions in which harmonisation efforts take place. Hence, our statements about convergence degrees or directions are not related to all countries and policies under investigation, but only to the affected sub-groups. It is important to emphasise that convergence within sub-groups affected by a certain mechanism can, but need not, result in convergence for the whole sample of countries and policies under investigation. 
To grasp the potential effects of certain mechanisms on all countries and policies under investigation, we rely on a further aspect, namely the scope of convergence. The scope of convergence increases with the number of countries and policies that are actually affected by a certain convergence mechanism, with the reference point being the total number of countries and policies under investigation. There is no straightforward relationship between degree and scope of convergence. Although it might often be the case that an increase in the number of converging countries actually reduces the variation among all countries, there are conceivable constellations in which the opposite might be the case /cf. chapter 5 for empirical results of the variation analysis]. For example, a sub-group of countries might converge towards a point far away from the other countries.

In view of the research questions underlying this study, we distinguish sub-groups of obligatory and non-obligatory policies; i.e., policies for which legally binding requirements at the international or supranational level are existent or absent. Moreover, we differentiate between policy items that are more or less likely to be affected by international trade (trade-related versus non-trade-related policies). These distinctions are based on several hypotheses which will be developed in more detail in the following sections. With regard to countries, it is of particular interest to distinguish subgroups according to their potential affectedness by the far-reaching harmonisation activities of the EU. Our country sample allows for a differentiation between founding members of the EU, countries participating in the different enlargement rounds, accession candidates, non-members closely associated with the EU (Norway and Switzerland), and non-members without particular association (Japan, Mexico and the US). Table 3.2 gives an overview of different indicators of policy convergence.

\subsubsection{Convergence on different policy dimensions}

In the literature, we generally find a broad list of policy dimensions on which convergence might occur, including, for instance, policy 
Table 3.2 Aspects of policy convergence

\begin{tabular}{|c|c|c|c|}
\hline Aspects & $\begin{array}{l}\text { Research } \\
\text { question }\end{array}$ & Reference point & Operationalisation \\
\hline $\begin{array}{l}\text { Convergence } \\
\text { degree }\end{array}$ & $\begin{array}{l}\text { How much } \\
\text { similarity } \\
\text { increase } \\
\text { over time? }\end{array}$ & $\begin{array}{l}\text { Sub-group of } \\
\text { countries } \\
\text { and policies } \\
\text { affected by } \\
\text { a certain } \\
\text { mechanism }\end{array}$ & $\begin{array}{l}\text { Decrease in standard } \\
\text { deviation over } \\
\text { time; sophisticated } \\
\text { sigma-convergence } \\
\text { based on paired } \\
\text { comparison }\end{array}$ \\
\hline $\begin{array}{l}\text { Convergence } \\
\text { direction }\end{array}$ & $\begin{array}{l}\text { In what } \\
\text { direction } \\
\text { lupward or } \\
\text { downward } \\
\text { shift of the } \\
\text { regulatory } \\
\text { mean|? }\end{array}$ & $\begin{array}{l}\text { Sub-group of } \\
\text { countries } \\
\text { and policies } \\
\text { affected by } \\
\text { a certain } \\
\text { mechanism }\end{array}$ & $\begin{array}{l}\text { Mean change; } \\
\text { delta-convergence } \\
\text { distance to best or } \\
\text { least performers }\end{array}$ \\
\hline $\begin{array}{l}\text { Convergence } \\
\text { scope }\end{array}$ & $\begin{array}{l}\text { How many } \\
\text { and which } \\
\text { countries } \\
\text { and policies } \\
\text { are } \\
\text { converging? }\end{array}$ & $\begin{array}{l}\text { All countries } \\
\text { and policies } \\
\text { under } \\
\text { investigation }\end{array}$ & $\begin{array}{l}\text { Number of countries } \\
\text { and policies }\end{array}$ \\
\hline
\end{tabular}

Source: Holzinger and Knill 2005c: 778.

output or content, policy style or process as well as policy outcomes (Bennett 1991: 418). Another, more encompassing differentiation is suggested by Dolowitz and Marsh (1996: 349-50), including 'policy goals, structure and content; policy instruments or administrative techniques; institutions; ideology; ideas, attitudes and concepts'. With regard to these dimensions, further differentiations have been applied. For instance, for the category of policy output - which is the particular focus of the underlying investigation - Hall (1993) distinguishes between policy paradigms, policy instruments and policy settings.

For the purpose of this study, we compare convergence effects on three different policy dimensions, namely, the extent to which countries have developed a specific policy or not with regard to 
a certain problem (policy presence), the policy instruments applied le.g., command-and-control regulation versus policies based on economic incentives\} as well as the settings of these instruments (i.e., levels of environmental standards). We expect significant differences in the degree of convergence across the different dimensions, as they imply different requirements with regard to the classification as 'similar' or 'dissimilar policy'.

For the dimension of policy presence, similarity is already given as soon as the countries in question adopt a political programme in response to a specific problem, regardless of the concrete instruments or instrument settings defined in the programme. It is obvious that convergence with regard to the dimension of policy presence can hence occur rather easily. The only condition is that countries respond politically to a certain problem; notwithstanding a potentially high level of variance across national responses |e.g., the application of command-and-control regulation versus self-regulation). By contrast, convergence on policy instruments requires not only that countries have enacted a certain policy, but also that they apply the same instruments within that programme. The similarity requirement is even more demanding when it comes to the dimension of settings, implying that countries have adopted policies that are based on similar instruments and their similar 'tuning' (in terms of similar standard levels or tax rates). These considerations lead to the following hypothesis:

\section{H 1 Policy dimension hypothesis}

The degree of policy convergence varies across different policy dimensions. It will be highest for the dimension of policy presence and lowest for the dimension of policy settings, regardless of the policy type.

At first glance, this expectation seems to be in contradiction with Hall (1993), who argues that policy change is most likely for policy settings but becomes increasingly difficult when it comes to policy instruments and paradigms. Changes in settings are considered rather 
unproblematic, as they can be achieved within existing instruments and paradigms. In a similar way, instrumental changes are considered to be more likely than paradigm changes, as the latter imply the departure from dominant and institutionally strongly entrenched ideas of how to perceive and resolve certain political problems.

This partial contradiction with our hypothesis can be resolved, however, when we examine more closely the dependent variables underlying Hall's study and our own investigation. Hall is concerned with the explanation of domestic policy change rather than crossnational policy convergence. The fact that domestic policy settings might be adjusted rather quickly and smoothly does not imply that different countries easily switch to similar settings. Given the 'high degrees of freedom' with respect to this policy dimension, i.e., the de facto infinite number of possible levels of regulation, convergence constitutes a rather demanding development, not least because it also requires that countries have adopted a respective policy and similar instruments in the first place. Moreover, the category of 'paradigm' does not exist in our three dimensions.

\section{$3 \cdot 3$ What CAUSES POLICY CONVERGENCE?}

The literature provides us with many potential factors that might lead to cross-national policy convergence (see Bennett 1991; DiMaggio and Powell 1991; Dolowitz and Marsh 2000; Drezner 2001; Hoberg 20011. Moreover, suggestions on causal factors can be found not only in studies explicitly concerned with policy convergence, but also in the literature on policy transfer, diffusion and isomorphism that is closely related to the study of convergence. Transfer and diffusion are processes that might result in convergence. Thus, the factors triggering these processes can be interpreted as potential causes of convergence. The same holds true for the mechanisms driving isomorphism - a concept that differs from convergence only with respect to its empirical focus on organisational structures (see chapter 2). Notwithstanding the broad variety of convergence causes emphasised in the literature, these factors basically refer to five distinct convergence 
mechanisms (Holzinger and Knill 2005a) that are presented in the following section.

\subsubsection{Overview of causal factors}

First, emphasis is placed on the harmonisation of national policies through international or supranational law. Countries are obliged to comply with international rules on which they have deliberately agreed in multilateral negotiations. Second, several studies emphasise convergence effects stemming from the imposition of policies. Imposition refers to constellations in which countries or international organisations force other countries to adopt certain policies by exploiting asymmetries in political or economic power. Third, cross-national policy convergence can be caused by communication and information exchange in transnational networks. Fourth, regulatory competition emerging from the increasing economic in tegration of European and global markets has been identified as one important factor that drives the mutual adjustment of policies across countries. Finally, cross-national policy convergence might simply be the result of similar, but independent, responses of different countries to parallel problem pressure (e.g., ageing of societies); i.e., policy convergence is caused by similar policy problems that countries are reacting to (Bennett 1991: 231).

As we are predominantly interested in the convergence effects caused by institutional and economic interlinkages among countries, we concentrate in the following on those mechanisms that are actually relevant in the context of our study, namely, international harmonisation, transnational communication and regulatory competition. This is not to deny the significance of other variables that are associated with convergence effects triggered by similar constellations of domestic policy problems. However, these variables will be considered as complementary rather than primary sources of explanation.

Moreover, and in contrast to the above-mentioned classification, we do not consider effects of imposition as a convergence 
mechanism in its own right. This can basically be traced to the fact that effects of imposition are hardly relevant for the sample of policies and countries under investigation in this book. On the one hand, constellations of a unilateral imposition of a policy on a country by another country or 'direct coercive transfer' (Dolowitz and Marsh 1996: 347) play no role in the context of our study. Such constellations, which might occur after a war, for example, are generally very rare and do not lead to far-reaching convergence, as they will hardly ever involve many countries. ${ }^{2}$

On the other hand, the second imposition scenario, namely conditionality exerted by international institutions, also applies only to a limited extent to our cases. First, conditionality is based on the exchange of policies for loans. For instance, it is argued that the spread of neo-liberal monetary and trade policies to Third World countries was driven by such conditionalities. Governments pressed by international financial institutions switched to liberal trade regimes (cf. Dolowitz and Marsh 1996: 347; Meseguer Yebra 2003). However, a comparable scenario of environmental policy convergence driven by financial and economic pressures through international institutions does not apply to our cases under investigation. A second form of conditionality, which is indeed potentially relevant for some of our countries under study, is the exchange of policy adjustments for membership in international institutions. It has been argued that the EU accession of CEE countries has been governed by this principle (Schimmelfennig and Sedelmeier 2004; Tews 2002). CEE countries willing to join the EU had to

${ }^{2}$ According to Bennett 'convergence by penetration' arises when states are forced to conform to actions taken elsewhere by external actors [1991: 227). His main examples are multinational businesses that exert pressure on governments to harmonise policies conceming products [1991: 228): However, as multinational firms can surely not force governments and as they have no political power, we subsume this kind of pressure for international cooperation under convergence through regulatory competition. Another example is voluntary international agreements, for instance at the level of the OECD and the Council of Europe (Bennett 1991: 228). In our view, these fall under the mechanism of transnational communication (promotion of policy models) rather than reflecting convergence through imposition. 
comply with the acquis communautaire and with the so-called Copenhagen criteria.

In line with this argument, we hence often find a distinction between harmonisation and imposition in the literature /cf. Bennett 1991; Dolowitz and Marsh 1996, 2000). This distinction is typically based on the extent to which international cooperation rests upon symmetric or asymmetric power relations between the involved states. However, we consider this differentiation to be unhelpful, as it is difficult to draw a clear analytical boundary between international negotiations characterised by symmetric or asymmetric relations of power. In negotiations at the international or European level, it will almost always be the case that some states are more influential than others. How can we judge whether the power constellations imply a voluntary or an imposed agreement from the perspective of individual countries? Why do scholars generally speak of conditionality with respect to the recent Eastern enlargement of the EU, but not with respect to earlier enlargement rounds, although in these cases also, accession was contingent upon the domestic adoption of the acquis communautaire?

In view of the fundamental analytical difficulties in drawing a distinction between harmonisation and imposition, we take the existence of international or supranational policies to which member countries or accession countries (by way of membership anticipation) adjust, as the decisive analytical starting point - regardless of the extent to which the adoption of these policies has been characterised by symmetric or asymmetric power relations between the involved countries. We therefore consider potential conditionality effects in the context of EU enlargement under the heading of (pre-accession) harmonisation rather than imposition.

The hypotheses on policy convergence we will formulate in section 4 are hence based on the distinction of the mechanisms of international harmonisation, transnational communication and regulatory competition. As summarised in table 3.3 , each mechanism combines an incentive and a corresponding response, i.e., the 
Table 3.3 Mechanisms of policy convergence

\begin{tabular}{|c|c|c|}
\hline Mechanism & Incentive & Response \\
\hline $\begin{array}{l}\text { International } \\
\text { harmonisation }\end{array}$ & $\begin{array}{l}\text { Legal obligation through } \\
\text { intemational law }\end{array}$ & Compliance \\
\hline \multicolumn{3}{|c|}{ Transnational communication } \\
\hline Lesson-drawing & Problem pressure & $\begin{array}{l}\text { Transfer of model } \\
\text { found elsewhere }\end{array}$ \\
\hline $\begin{array}{l}\text { Transnational } \\
\text { problem-solving }\end{array}$ & Parallel problem pressure & $\begin{array}{l}\text { Adoption of } \\
\text { commonly } \\
\text { developed model }\end{array}$ \\
\hline Emulation & Desire for conformity & $\begin{array}{l}\text { Copying of widely } \\
\text { used model }\end{array}$ \\
\hline $\begin{array}{l}\text { International } \\
\text { policy } \\
\text { promotion }\end{array}$ & Legitimacy pressure & $\begin{array}{l}\text { Adoption of } \\
\text { recommended } \\
\text { model }\end{array}$ \\
\hline $\begin{array}{l}\text { Regulatory } \\
\text { competition }\end{array}$ & Competitive pressure & Mutual adjustment \\
\hline \multicolumn{3}{|l|}{ Other factors } \\
\hline $\begin{array}{l}\text { Parallel problem } \\
\text { pressure } \\
\text { Political demand }\end{array}$ & $\begin{array}{l}\text { Parallel domestic } \\
\text { constellation }\end{array}$ & $\begin{array}{l}\text { Independent similar } \\
\text { response }\end{array}$ \\
\hline
\end{tabular}

Source: adapted from Holzinger and Knill 2005c: 780.

behaviour actually leading to convergence. The causal mechanism leads to convergence, if the response actually occurs.

\subsubsection{International harmonisation}

The mechanism of international harmonisation leads to crossnational convergence if the involved countries comply with uniform legal obligations defined in international or supranational law. Harmonisation refers to a specific outcome of international cooperation, namely to constellations in which national governments are legally required to adopt similar policies and programmes as part of their obligations as members of international institutions. 
International harmonisation and more generally international cooperation presuppose the existence of interdependencies or externalities which push governments to resolve common problems through cooperation within international institutions, hence sacrificing some independence for the good of the community (Drezner 2001: 60; Hoberg 2001: 127). Once established, institutional arrangements will constrain and shape the domestic policy choices, even as they are constantly challenged and reformed by their member states. This way, international institutions are not only the object of state choice, but at the same time consequential for subsequent governmental activities (Martin and Simmons 1998: 743).

\subsubsection{Transnational communication}

Under the term 'transnational communication' we summarise a number of different but related mechanisms, including lessondrawing, transnational problem-solving, emulation and the transnational promotion of policy models. They have in common that their operation is purely based on communication among countries. By contrast, the other mechanisms presuppose legal obligation (harmonisation) or competitive pressure (regulatory competition). Communication might also play a role in these cases; however, it is not the main factor accounting for convergence effects. So far, in the literature no established heading for these different, but closely related, mechanisms exists. One could certainly argue that each of the mechanisms summarised under transnational communication can be considered as a mechanism in its own right. However, they share an important characteristic that crucially distinguishes them from all other causal mechanisms: namely, they presuppose nothing but information exchange and communication with other countries.

Lesson-drawing The mechanism of lesson-drawing refers to constellations of policy transfer in which governments rationally utilise available experience elsewhere in order to solve domestic problems. According to Rose, who introduced the concept, lesson-drawing is 
based on a voluntaristic process whereby government $A$ learns from government B's solution to a common problem what to do ('positive lessons') or what not to do ('negative lessons'). The government is modelled as a rational actor who poses the question: 'Under what circumstances and to what extent would a programme now in effect elsewhere also work here?' (Rose 1991: 4). The creation of new programmes, however, need not be based on the mere copying of other policies, but can take many different forms, ranging from hybrids of transferred and domestically developed components to completely new models. Rose also emphasises that drawing a lesson does not require policy change: a programme elsewhere may be evaluated negatively or there may be no way to transfer it (Rose 1991: 22). Therefore, lesson-drawing is not the same as policy convergence.

A closely related concept is presented by Meseguer Yebra (2003) who applies the concept of Bayesian learning to policy learning. Bayesian learning is a mode of rational, experience-based learning. Governments are modelled as perfectly rational learners. They update their beliefs on the consequences of policies with all available information about policy outcomes in the past and elsewhere. They choose the policy that is expected to yield the best results (Meseguer Yebra 2003). Bayesian learning is a formal mechanism, but the notion of learning in this concept is very similar to Rose's concept of lesson-drawing. However, in Meseguer Yebra's approach, governments will converge in their policy choices if they are exposed to the same information. This implies that there is a 'best solution' given a certain state of information. However, only if governments are not perfectly rational and do not collect all available information, may divergence occur.

Transnational problem-solving Similar to lesson-drawing, transnational problem-solving assumes processes of rational learning. In the latter case, however, convergence is not the result of bilateral transfer. Rather, it is driven by the joint development of common 
problem perceptions and solutions to similar domestic problems and their subsequent adoption at the domestic level. Transnational problem-solving typically occurs within transnational elite networks or epistemic communities, defined as networks of policy experts who share common principled beliefs over ends, causal beliefs over means and common standards of accruing and testing new knowledge (Haas 1992: 3). Common educational and normative backgrounds typically facilitate joint development of common policy models in such constellations (DiMaggio and Powell 1991: 73).

It is easily conceivable that transnational problem-solving in elite networks can prepare the ground for subsequent activities of international harmonisation. This holds true especially for problems characterised by strong interdependencies. At the same time, however, it is emphasised that international institutions play an important role in forging and promulgating transnational epistemic communities [Elkins and Simmons 2005). In other words, regular negotiations and discussions on problems subject to harmonisation provide the ground for joint problem-solving in related areas that do not necessarily require a joint solution through international law. This argument is supported by the findings of Kern (2000: 144) who shows that international institutions play an important role in accelerating and facilitating cross-national policy transfer. They constitute important channels for multilateral communication and policy diffusion. Kern shows that - compared to policy exchange resting on bilateral and horizontal communication between countriespolicy models spread much broader and faster if these countries are members of the same international institution.

Emulation of policies Policy convergence through emulation is driven by the mere desire for conformity with other countries rather than the search for effective solutions to given problems. Consequently, emulation usually implies the simple copying of policies adopted elsewhere. Which factors account for this search for conformity? In the literature, various aspects are mentioned. 
First, it is argued that emulation is a function of the number of countries that have already adopted a certain policy. As argued in herding theories, it can be optimal for a country to follow the behaviour of others even without using further information than the sheer number of followers. The fact that many others apply a certain policy serves as information that this might be the best thing to do (Levi-Faur 2002). In theories of population ecology, a different rationale is emphasised: emulation is the result of the socially embedded behaviour of actors (Baum and Oliver 1992; Meyer and Rowan 1977). The most widespread solution to a problem becomes the obvious way of dealing with it whereas other possible solutions are no longer considered.

Second, emulation can be driven by the striving of organisations to increase their social legitimacy by embracing forms and practices that are valued within the broader social and institutional environment (DiMaggio and Powell 1991: 70). States might sometimes copy mimetically the policies of other states simply to legitimate conclusions already reached (Bennett 1991: 223).

Third, a psychologically based rationale for emulation is the desire of actors 'not to be left behind', a mechanism that has been transferred to the behaviour of state actors within the international system (Finnemore 1996; Meyer et al. 1997; Tews 2002). In the theory of DiMaggio and Powell 'mimetic isomorphism' occurs especially when an innovation is poorly understood and when its consequences are still unclear (1991: 69). The fear of being left behind might be a result of uncertainty, but might also be a motive in itself.

Fourth, there are rational motivations. Bennett observes that emulation might be a consequence of time pressures: 'the more urgency that is perceived, the more likely will be the imitation of solutions without lengthy analysis and investigation' (1991: 223). Moreover, compared with more demanding forms of learning, the costs of information are probably much lower for simple imitation (Tews 2002: 180). 
International policy promotion Countries might not only be inspired to adopt a certain policy because of rational learning or their desire for conformity. They can also be motivated to do so because of legitimacy pressures emerging from the promotion of policy models by international institutions. ${ }^{3}$ In contrast to the mechanism of transnational problem-solving, policy convergence is not the result of joint problem-solving efforts of countries represented in transnational networks, but is driven by the active role of international institutions that are promoting the spread of distinctive policy approaches they consider particularly promising.

Cross-national policy transfer is stimulated by non-binding international agreements or propositions on broad goals and standards that national policies should aim to achieve, institutionalised peer review and identification of best practice (benchmarking) as well as the construction of league tables ranking national policies in terms of performance to previously agreed criteria (Humphreys 2002: 54; Tews 2002: 174). International institutions, such as the EU, the OECD or the World Bank, but also NGOs and transnational interest organisations (Keck and Sikkink 1998), play a highly active role in this process. In constantly searching for new policy ideas, disseminating best practice and evaluating domestic policy performance, they function as mediators of cross-national policy transfer, urging national governments to adopt successful policy models (Kem, Jörgens and Jänicke 2000: 10). Countries that deviate from recommended policy models or rank low in international league tables face pressure to legitimate their policy approaches in light of 'international scrutiny'.

In many instances, promotion activities by international institutions originate from the activities of individual states seeking to convince other countries to copy their policy models. Countries

\footnotetext{
${ }^{3}$ Policy promotion need not be restricted to the activities of international institutions, but can also be pursued by individual countries, i.e., on a bilateral basis. One example is the Dutch activities to promote the National Environmental Policy Plan during the 1990s (Licfferink 1999).
} 
which have developed innovative policy concepts generally have a strong interest to establish their approach as an international solution in order to minimise costs of institutional and economic adjustment to potentially diverging internationally promoted policy models. This pattern of leaders using international institutions as leverage when trying to drag along the laggards has not only been observed in the EU (Andersen and Liefferink 1997; Héritier, Knill and Mingers 1996), but also at the level of the OECD and other international institutions (Jänicke 1998: 334; Wallace 1995: 2671.

\subsubsection{Regulatory competition}

While the mechanism of international harmonisation is based on domestic compliance with legal obligations, regulatory competition is expected to lead to cross-national convergence, as countries facing competitive pressure mutually adjust their policies. Regulatory competition presupposes economic integration among countries. Especially with the increasing integration of European and global markets and the abolition of national trade barriers, the international mobility of goods, workers and capital puts competitive pressure on the nation states to redesign domestic market regulations in order to avoid regulatory burdens restricting the competitiveness of domestic industries. The pressure arises from (potential) threats of economic actors to shift their activities elsewhere, inducing governments to lower their regulatory standards.

This way, regulatory competition among governments may lead to a race-to-the-bottom in policies, implying policy convergence (Drezner 2001: 57-9; Hoberg 2001: 127; Simmons and Elkins 2004). Theoretical work, however, suggests that there are a number of conditions that may drive policy in both directions (Holzinger 2002, 2003; Kern, Jörgens and Jänicke 2000; Scharpf 1997; Vogel 1995), including, for example, the type of policy concerned (product or process standards|, or the presence of interests other than business in national politics. 


\subsubsection{Other factors}

It is the central objective of this study to analyse the extent to which international economic and institutional interlinkages among countries lead to similarity increases in their environmental policies. In focusing on the three causal mechanisms described above, however, we do not imply that other convergence causes might not be relevant. We therefore discuss other explanatory factors of convergence mentioned in the literature. This way, we are able to make a more comprehensive judgement about the relative explanatory power of the international convergence causes in which we are primarily interested.

The factors addressed in the following are closely related to the fact that convergence of policies between several countries can arise as a result of similar but independent responses of political actors to parallel problem pressures. Just as individuals open their umbrellas simultaneously during a rainstorm, governments may decide to change their policies in the presence of tax evasion, environmental pressures, such as air pollution, or an ageing population. ${ }^{4}$ As Bennett notes, the analyst of policy convergence 'must avoid the pitfall of inferring from transnational similarity of public policy that a transnational explanation must be at work' (1991: 231).

In the context of environmental policy parallel problem pressure relates to two factors. First, the presence of certain environmental problems might trigger some governmental response to combat these problems. Second, the same is true for the presence of political demand for environmental policy exerted by green movements, green parties or the general public. Both factors are correlated to some degree, as it is unlikely (although conceivable) that an environmental movement will develop when there are no environmental problems. However, the presence of environmental problems

${ }^{4}$ This phenomenon has also been discussed under the names of functional, technocratic or technological determinism [Bennett 1988: 417, Rose 1991: 9], clustering (Simmons and Elkins 2004), spurious diffusion (Gilardi and Braun 2005; Gilardi 2005), or parallel domestic pressures (Hoberg 2001: 127). 
does not necessarily imply the existence of an environmental movement. Thus, both factors have to be taken into account for the analysis of convergence.

First, similar policy responses can be the result of similar environmental pressures different countries are confronted with. Environmental problem pressure can be generally assumed to increase with population density and can thus be approximated by this indicator. Other indicators are the levels of certain emissions or environmental quality factors. One prominent indicator in this respect is $\mathrm{CO}_{2}$ emissions, since they arise from a whole range of activities damaging the environment. Second, it is argued that similar policy responses are driven by similarity in political demand. In this context, the number and influence of environmental organisations and the existence and influence of green parties can be seen as the most important factors.

In addition to the above-mentioned indicator, two variables have to be emphasised that affect both environmental pressure and demand for environmental policies. On the one hand, the cultural similarity among countries (e.g., in terms of legal traditions, historical heritage, language, religion or geographical proximityl plays an important role in this respect. It not only facilitates the transfer and emulation of policies, hence leading to increases in crossnational policy similarity over time, but also implies that the political process of defining and addressing environmental problems is characterised by similar patterns. In a similar way, it can be argued that the extent to which countries already pursue rather similar policies and regulatory approaches (i.e., the pre-existing similarity) plays an important role in rendering cross-national policy transfer more or less difficult.

On the other hand, an important indicator affecting both environmental pressure and political demand is the level of income in a country. The so-called 'Environmental Kuznets Curve' (Panayotou 1993; Stern and Common 2001/ indicates that the level of environmental pollution grows with the GDP up to a certain point, but 
then decreases again. ${ }^{5}$ The usual explanation for this shape points at two factors. First, economic structure is assumed to account for the level and structure of environmental problems: the more industrialised a country is the more environmental pollution problems will be present. More industrialised countries are usually richer than rural societies (Panayotou 1993; Syrquin 1988). Second, the richer a country is the higher is the political demand for environmental protection. Environmental policy is a luxury good and thus demand for it grows with the level of income (Beckerman 1992; Boyce 2004). Thus, similar income levels should imply similar environmental policies.

\subsection{WHEN DOES POLICY CONVERGENCE OCCUR?}

Having identified the causal mechanisms of policy convergence, it is the objective of this section to develop theoretical expectations about the conditions of their operation. We aim at further specifying the mechanisms in order to develop testable hypotheses with respect to degree, direction and scope of cross-national policy convergence for each mechanism. To answer these questions, a point of reference is needed. As a reference point, we assume a situation where no mechanism is at work and where the policies of the countries under consideration are characterised by diversity.

Although we are aware of the fact that countries might be exposed to several mechanisms of convergence and that these mechanisms might interact (cf. Holzinger and Knill 2005a), the following considerations are based on the analysis of the isolated effects of different mechanisms. Our primary interest is to theoretically investigate the effects and operation of individual convergence mechanisms.

\subsubsection{International harmonisation}

The scope of cross-national convergence triggered by international harmonisation is affected by two factors. First, as convergence effects

\footnotetext{
The Kuznets curve is an inverse U-shaped curve.
} 
are restricted to those countries that are actually committed to international agreements or supranational regulations, the scope of convergence through harmonisation increases with the number of countries that are members of the respective international institution or regime with the power to enact legally binding rules. Second, the number of policies affected through harmonisation increases with the number of areas covered by the legislation of the international organisation in question.

With regard to the extent to which international harmonisation triggers cross-national convergence, two factors can be identified. First, the degree of convergence varies with the legal specification of international law. Specification is particularly high, if international law requires the total or minimum harmonisation of national standards. Convergence effects are less pronounced, by contrast, if legal rules are defined in a less rigid way, leaving member states broad leeway for selecting appropriate instruments to comply with international policy objectives. In this respect, varying discretion levels are conceivable, ranging from differentiated regulatory requirements, the prescription of broad objectives rather than detailed substantive or procedural regulations, to mutual recognition and opting-out clauses.

Second, the degree of similarity will increase with the extent to which compliance with legal obligation can actually be enforced. International institutions reveal important differences in terms of their enforcement powers (see Abbott and Snidal 1998). The EU can be characterised as an institution in which such powers are comparatively well developed, given the direct effect and the supremacy of European law, the influential role of the European Court of Justice in the enforcement of Community law, the - albeit restricted monitoring activities of the European Commission as well as the opportunity financially to sanction non-compliant member states (see Zürn and Joerges 2005). Against this background, the converging effects of European legislation can be expected to be higher than those of intergovernmental organisations or international regimes, where enforcement powers are less developed. 
To what extent does convergence through international harmonisation coincide with upward or downward shifts of the regulatory mean? The answer to this question basically depends on factors such as decision rules, interest constellations and the distribution of power between the involved actors /typically national governments and international organisations], which shape the negotiations at the level of international institutions. Theoretical modelling generally predicts an outcome which reflects a compromise, hence lying somewhere between countries favouring extreme positions of either rather strict or weak regulations, with a strong tilt towards the preferences of the more powerful states (Drezner 2001: 61; for the EU: Holzinger 1994: 465-8; Tsebelis 2002: chapter 11). With regard to environmental policy, several factors favour the view that harmonisation implies an overall increase in the strictness of regulatory levels; i.e., a compromise that is closer to the strictest rather than weakest regulatory level found in the member states of the international institution in question.

First, it has been argued by several authors (Holzinger 2003; Scharpf 1997; Vogel 1995) that in certain constellations those countries preferring stricter levels of environmental regulation are more influential in international negotiations, implying that international harmonisation takes place at the top rather than the bottom level. This argument has been developed in particular for the case of product standards. In this case, all member states (regardless of their preference for strict or weak standards) share a common interest in international harmonisation in order to avoid market segmentation as a result of different national product requirements (Holzinger 2002: 69). While all countries share a common interest in harmonisation, those states with a preference for strict standards are in a stronger position to put through their preferences in international negotiations. On the one hand, the trade regimes of the EU (Art. 30 TEU) and the WTO - for reasons of health and safety protection allow high-regulating countries to ban the import of products that are not in line with the strict domestic standards. As all countries 
share an interest in international harmonisation, high-regulating countries are therefore in certain cases able unilaterally to impose their strict standards as the international rule. Based on this argument, we should expect that - at least for product standards - international harmonisation implies an upward shift of the regulatory mean.

Second, especially for harmonisation at the level of the EU, additional structural features of the policy-making process might favour an upward shift for other policy types /production standards and non-trade-related policies) for which the above-mentioned interest constellation favouring harmonisation at the top does not apply. The fact that we observe European harmonisation at the top rather than the bottom of existing member state regulations also in these areas (cf. Knill 2003: 73-88) has been explained by particular dynamics emerging from a regulatory contest in influencing EU policies between the member states (Héritier, Knill and Mingers 1996).

These dynamics emerge from the interest of national governments to minimise institutional costs of adjusting domestic regulatory arrangements to EU policy requirements. Especially high-regulating countries with a rather comprehensively and consistently developed regulatory framework of environmental policies and instruments might face considerable problems of adjustment, if European policies reflect regulatory approaches and instruments that depart from domestic arrangements. As a result, these countries have a strong incentive to promote their own concepts at the European level. In so doing, the most promising way is to rely on the strategy of the 'first move', i.e., to try to shape European policy developments early on, during the stages of problem-definition and agenda-setting. This requires that member states have to win the support of the EU Commission, which has the formal monopoly to initiate policies at the EU level. The Commission, in turn, is generally interested in strengthening and extending supranational policy competencies. As a consequence, only those domestic initiatives that fit with these objectives of the Commission have a chance of 
succeeding. This specific interaction of national and supranational interests favours the development of innovative and ambitious policies at the EU level, hence driving EU harmonisation more towards the top rather than the bottom of domestic regulation levels |Knill 2003: $131-4 \mid$.

Third, even if we assume that the final agreement only lies in the middle between high-regulating and low-regulating countries, there is still a high probability that the mean of national regulatory levels becomes stricter. This can be traced to the fact that by far the largest part of environmental standards follows the principle of minimum rather than total harmonisation. In the case of minimum harmonisation, it is still possible for countries with a preference for higher regulatory levels to enact standards beyond the minimum level specified in international agreements. ${ }^{6}$ In contrast to total harmonisation, deviations to the top are therefore still possible, while countries with lower standards are obliged to raise their standards at least to the international minimum level. Given the dominance of minimum harmonisation, we thus predict that international environmental policy cooperation is likely to result in shifting the regulatory mean upward. This expectation rests on the assumption that not all high-regulating countries will lower their standards towards the minimum level.

\section{H 2 Harmonisation hypotheses}

H 2.1 Degree of convergence

The degree of convergence through harmonisation increases with the obligatory potential of international or supranational insti. tutions (as expressed by the specification of international legal requirements and the capacities of the organisation to enforce the national transposition as well as compliance with these legal obligations).

${ }^{6}$ In the EU, for instance, this possibility is regulated in Article 95 TEU [Knill 2003: 127). 
H 2.2 Direction of convergence

International harmonisation leads to stricter levels of regulation in the member countries. These effects are more pronounced for the EU than for other international organisations.

In summary, it is therefore likely that the international harmonisation of environmental standards coincides with an overall increase in the strictness of domestic regulatory levels. In this context, we expect that the effects of strengthening of EU harmonisation are more pronounced than upward shifts resulting from harmonisation activities of other international regimes. This expectation is based on the fact that the structural dynamics emerging from a regulatory contest between the member states in order to influence the respective policy developments constitute a specific feature of the EU political system.

\subsubsection{Transnational communication}

With respect to the number of countries and policies potentially affected by transnational communication, only a few restrictions apply, given the rather undemanding precondition of information about policy choices of other countries. It is therefore impossible to identify factors that restrict the scope of convergence through transnational communication for certain policies or countries.

The fact that transnational communication might potentially affect all countries and policies under investigation does not imply, however, that this mechanism produces cross-national policy convergence in each constellation. Rather, its operation varies with several factors. First, research on emulation emphasises that the probability of adoption increases with the number of countries that have already switched to a certain policy model (Bikhchandani, Hirshleifer and Welch 1992; Levi-Faur 2002). In other words, the degree of pre-existing policy similarity across countries crucially affects the likelihood of future similarity changes through emulation.

Second, as argued in the literature on lesson-drawing, the degree of convergence varies with the extent to which countries share 
cultural linkages. In their search for relevant policy models, decisionmakers are expected to look at the experiences of those countries with which they share an especially close set of cultural ties [Strang and Meyer 1993). Especially in constellations characterised by high uncertainty about the consequences of policy choices, decisionmakers are likely to imitate the practices of nations with which they share linguistic, religious, historical or other cultural linkages [Friedkin 1993; Simmons and Elkins 2004].

Third, as information and knowledge exchange between states is the essential requirement for most transnational communication mechanisms to become effective (Simmons and Elkins 2004), the degree of convergence will be particularly high among those countries that are strongly interlinked in varying transnational networks. Of particular importance in this respect is common membership in international institutions that play an important role in increasing the interaction density between their members, hence intensifying transnational information exchange (Kern 2000: 267).

To what extent does convergence through transnational communication lead to shifts in the level of domestic regulations? One could certainly argue that the fact that states adopt a certain innovation or copy policy concepts successfully applied in other countries need not automatically imply that this results in an increase in regulatory levels. However, as with international harmonisation, there are several theoretical arguments that let us expect that the effects of transnational communication also imply an increase in the strictness of domestic levels of regulation.

First, it has been emphasised that in processes of policy-learning, the involved actors rely on 'cognitive heuristics'. Rather than relying on all available information on policy developments and respective effects from abroad, national governments pursue a more selective approach, focusing on specific 'reference models'. A first pattern that can be observed is the concentration on countries or international organisations which enjoy high experience and reputation with respect to their problem-solving capacity in a certain policy area 
(Dobbin, Garrett and Simmons 2003; Rose 1991). This focus on 'miracle models' (Meseguer Yebra 2003; Simmons and Elkins 2004) has also been reported for the role of environmental pioneer countries (Andersen and Liefferink 1997). Rather than looking at 'best countries', a second heuristic is to search for 'best policies', i.e., national governments explore successfully applied models that fit most with their specific problem constellation, implying an orientation towards similar countries, for example in terms of cultural similarity (Brune and Garrett 2000; Rose 1991; Simmons and Elkins 2004). Both patterns imply that governments adjust their policies to pioneer models or countries that either generally or at least related to a certain cultural space enjoy a high degree of reputation in terms of their problem-solving capacity. This orientation can hence hardly be expected to coincide with a lowering of regulatory standards, but will typically imply an increase in the strictness and comprehensiveness of environmental regulation.

Second, upward shifts of regulatory levels are triggered by the communicative influence of international organisations. This holds true in particular with regard to their role in the promotion of policy models based on the dissemination and evaluation of what they consider as 'best practice'. This competition of ideas can generally be expected to result in an overall strengthening of regulatory concepts. Since international organisations will in general promote the most progressive national approach, benchmarks will be set at the level of the highest-regulating country. Hence, an upward shift of the mean will be the likely result.

\section{H 3 Communication hypotheses}

\section{H 3.1 Degree of convergence}

The degree of convergence through transnational communication increases with the communicative potential of the institution in question (as expressed by the interaction density and breadth among its member states).

\section{H 3.2 Direction of convergence}

Transnational communication leads to stricter levels of regulation in the involved countries. 


\subsubsection{Regulatory competition}

A number of conditions can be derived from theories of regulatory competition (Holzinger 2003; Scharpf 1997; Vogel 1995), which affect our convergence aspects. To begin with, these theories point to various factors that restrict the scope of potentially converging countries and policies. On the one hand, potential convergence effects of regulatory competition presuppose economic integration between market economies. Even in constellations of high economic integration, no competitive pressures will emerge in and between non-market economies. This scenario applies in particular to the CEE countries before 1990 . On the other hand, a qualification applies to the policies for which convergence effects are predicted. Adjustments will be most pronounced for trade-related policies, such as product or process standards. No convergence is expected for policies which are subject to low competitive pressures from international markets. This holds true for all policies that are not directly related to products or to production processes, such as nature or bird protection policies. It holds also true if trade-related policies are concerned, but the effects of the regulation on production costs are low. In this case they do not affect competition between industries in different countries.

In general, theories of regulatory competition predict that countries adjust policy instruments and regulatory standards in order to cope with competitive pressures emerging from international economic integration. The more exposed a country is to competitive pressures following from high economic integration lemerging from its dependence on trade of goods, capital and services with other countries) the more likely it is that its policies will converge to other states with international exposure. In other words, the degree of convergence depends on the level of competitive pressures to which countries are exposed.

There is an ongoing debate in the literature on the direction of convergence caused by regulatory competition. Often a distinction is made between product and production process standards (Holzinger 2003; Scharpf 1997). In the case of process standards, we find a widely 
shared expectation that policy convergence will occur at the lowest common denominator; states will gravitate towards the policies of the most laissez-faire country (Drezner 2001). If the regulation of production processes implies an increase in the costs of production, potentially endangering the international competitiveness of an industry, regulatory competition will generally exert downward pressures on economic regulations (Scharpf 1997: 524). It is assumed that governments are ready to lower environmental standards in the face of lobbying and exit threats exerted by the respective industry.

Expectations are less homogeneous for product standards. While industries in both low-regulating and high-regulating countries have a common interest in harmonisation of product standards to avoid market segmentation, the level of harmonisation can hardly be predicted without the examination of additional factors. Most important in this context is the extent to which high-regulating countries are able to enforce stricter standards. If it is possible to erect exceptional trade barriers, as for example for health or environmental reasons under EU and WTO rules, convergence at a high level of regulation is to be expected. If such exceptional trade barriers cannot be justified, by contrast, competitive pressure will induce governments to lower their standards (Holzinger 2003: 196; Scharpf 1997; Vogel 1995).

As such exceptional trade barriers can usually be justified in the environmental sector (see above) we expect that a downward shift of the regulatory level will only occur in the case of process standards. Based on the arguments presented above and in the previous sections, we hypothesise that regulatory competition will lead to an upward shift of environmental regulation in the case of product standards.

\section{H 4 Regulatory competition hypotheses}

H 4.1 Degree of convergence

The degree of convergence increases with the competitive pressures to which countries are exposed (emerging from their dependence on trade of goods, capital and services with other countries). 


\section{H 4.2 Direction of convergence}

Regulatory competition leads to stricter levels of regulation for product standards, while for process standards a weakening of regulatory standards is expected.

\subsubsection{Other factors}

Bennett identifies two conditions for parallel problem pressure to lead to the same solution (1988: 419). First, there must be certain intrinsic characteristics of a problem that would inevitably lead to its similar treatment. Second, these characteristics must be universally recognised. The problem with this argument, however, is that the extent to which convergence might be observed is strongly dependent on the definition of 'similar treatment'.

If similarity is defined in a very demanding way, including, for instance, the choice of instruments and regulatory settings, there will rarely be only one solution to a problem (Hoberg 1991; Rose 1991: 9]. This is already valid for a relatively simple problem, such as the rainstorm mentioned above. Although many people may open their umbrellas, others may put on a hat, or seek shelter.

If we apply a less demanding definition of similarity, by contrast, there is a higher probability that we observe convergence as a result of parallel problem pressure. For example if the problem is that it starts raining, and the 'similar solution' is that people react to it, we will probably find convergence, as most people will in fact react somehow. Or, if the problem is the ageing of society, and the solution is that the pension schemes are changed, we might also find convergence, as most governments will change pension schemes. This implies, however, still a comparatively low degree of convergence, as the new pension schemes may be very different.

As the bandwidth of possible solutions or reactions to a problem is usually very broad, in the case of parallel problem pressure convergence can be expected only in very general terms (in the sense of mere reaction). A higher degree of convergence can be expected only if some additional conditions are fulfilled, for example, if similarity 
in environmental pressures and political demand of the affected countries is high. In other words, countries that share a broad number of characteristics are more inclined to independently react to a problem in a similar way (Lenschow, Liefferink and Veenman 2005).

Following our considerations in section 3.3.5 above, we therefore expect that countries are more likely to develop similar environmental policies over time the more they reveal or develop similarities with regard to the following characteristics: population density, emission levels $\left(\mathrm{CO}_{2}\right.$ emissions $)$, the existence and influence of green parties, cultural similarity and income levels, as well as existing policies.

This way structural similarity may not only affect the degree of convergence among countries reacting to parallel problem pressures, but will also imply an overall increase in the strictness of regulatory standards. It is highly plausible that an increase in environmental pressures leads to respective adjustments in terms of more comprehensive regulatory approaches and stringent regulatory requirements. At the same time, an increase in political demand should lead to higher levels of protection.

\section{H 5 Hypotheses on other variables}

H 5.1 Degree of convergence

The degree of convergence increases with the degree of existing similarities between countries with respect to culture, income levels, demand for environmental protection, problem pressure as well as existing environmental policies.

\section{H 5.2 Direction of convergence}

The strictness of environmental regulation increases with the levels of income and environmental problem pressure as well as the demand for environmental protection.

\subsection{CONCLUSION}

In this chapter, we analysed various causes and factors regarding the scope, degree and direction of cross-national policy convergence. 
Starting from the literature on convergence and related concepts, we developed theoretical expectations on the main causal mechanisms suggested by these theories. From these considerations several general conclusions can be drawn.

First, our analysis shows that one should not expect a general increase in the scope and degree of cross-national policy convergence. This is valid not only for the overall picture of the causes of policy convergence, but also for the individual causal mechanisms. Even if the mechanisms have an effect on policy convergence, it is - as a result of their different scope conditions - by no means justified to expect global convergence over all countries, policy areas and policy dimensions. As demonstrated by our analysis, the conditions and effects of convergence vary strongly across the different convergence mechanisms.

Second, we can generally expect an upward shift of the regulatory level of environmental standards. While regulatory competition may lead to a downward shift of the average policy in the case of process standards, the other mechanisms seem to imply a constant move towards stricter environmental policies. 